\title{
Comunicação
}

[Communication $]$

\section{Desempenho e termorregulação de porcas lactantes alojadas em diferentes localizações no interior de um galpão com sistema de resfriamento evaporativo em ambiente tropical}

\author{
[Performance and thermoregulation of lactating sows housed in different \\ locations inside a shed with an evaporative cooling system \\ in a tropical environment]
}

\author{
E.J. Rigo, M.R.B. Mattos Nascimento ${ }^{*}$, N.A.M. Silva
}

Universidade Federal de Uberlândia - Uberlândia, MG

Conhecer a zona termoneutra dos suínos é importante. Os animais criados sob temperatura ambiente ideal têm menor gasto energético para manter o equilíbrio térmico e, consequentemente, sua produção, reprodução e bem-estar não são prejudicados. Williams et al. (2013) consideraram termoneutralidade temperaturas de 18 a $20^{\circ} \mathrm{C}$ e, como estresse por calor, de 24 a $30^{\circ} \mathrm{C}$, para fêmeas suínas durante a gestação, lactação e pós-desmame. A umidade do ar ideal é de 50 a $70 \%$, não devendo ultrapassar $70 \%$ (Sampaio et al., 2004), e o valor do índice de temperatura e umidade (ITU) até 74 é considerado sem estresse por calor (Wegner et al., 2016).

Efeitos negativos das altas temperaturas sobre as matrizes suínas lactantes levaram ao desenvolvimento de alguns sistemas de resfriamento, por exemplo: o uso do sistema de ventilação por pressão positiva, resfriamento da cabeça da porca e resfriamento evaporativo combinado com ventilação por pressão negativa. Esses sistemas têm a finalidade de melhorar a condição térmica, reduzir os efeitos das altas temperaturas e melhorar o bem-estar dos animais, para, assim, diminuir perdas na produtividade.

Estudos têm investigado os diferentes sistemas de controle do ambiente térmico em galpões de fêmeas suínas em lactação. O sistema de

Recebido em 18 de março de 2019

Aceito em 19 de março de 2019

* Autor para correspondência (corresponding author)

E-mail:maran@ufu.br resfriamento evaporativo com pressão negativa foi mais eficiente que os de resfriamento na nuca e manejo de cortina na redução da temperatura do ar (Morales et al., 2013). No verão, Justino et al. (2015) verificaram que o resfriamento direcionado à região da cabeça da porca em lactação auxiliou na sua termorregulação e aumentou a massa corporal dos leitões ao desmame em relação ao grupo de fêmeas mantidas na mesma sala de maternidade, porém sem receber o resfriamento da cabeça. Perin et al. (2016) concluíram que fêmeas suínas lactantes que receberam resfriamento da nuca apresentaram desempenho superior às matrizes alojadas em galpão com manejo de cortinas.

Entretanto, não foram encontradas, na literatura consultada, pesquisas que tivessem avaliado a uniformidade do ambiente térmico ao longo do galpão com sistema de resfriamento evaporativo combinado com pressão negativa para matrizes suínas lactantes. Portanto, objetivou-se neste estudo avaliar o ambiente térmico em diferentes localizações no interior de um galpão, próximo ao pad cooling (leste), centro e próximo aos exaustores (oeste) de um galpão de maternidade e as variáveis fisiológicas de termorregulação, desempenho reprodutivo e produtivo de matrizes suínas e da leitegada, no verão.

O estudo foi aprovado, com o registro CEEA068/2016, pelo Comitê de Ética e Experimentação Animal da Universiade de Uberaba-Uniube. Esta pesquisa foi realizada em 
uma granja comercial produtora de suínos desmamados (UPD), localizada em Bom Jesus dos Campos, MG, (latitude 20 46' 01.4"S, longitude $46^{\circ} 12^{\prime} 26.4^{\prime \prime} \mathrm{W}$, e altitude $830 \mathrm{~m}$ ), Brasil, em janeiro de 2017.

Trinta e quatro matrizes suínas de composição genética $50 \%$ Landrace $/ 50 \%$ Large White, todas da linhagem comercial Topigs $20^{\circledR}$, foram alojadas em um galpão de maternidade com, respectivamente, 111,$00 ; 10,20$ e $2,95 \mathrm{~m}$ de comprimento, largura e pé direito, coberto com telha de barro com beiral de $1,10 \mathrm{~m}$, mureta de $0,80 \mathrm{~m}$ de altura, com as laterais de telas metálicas e cortinas e forro de face prata. Este era constituído de resfriamento evaporativo combinado com pressão negativa, com quatro exaustores de 1,30 metro de diâmetro no lado oeste, e dois painéis evaporativos com $7,17 \mathrm{~m} \mathrm{x}$ $1,90 \mathrm{~m}$, instalados no lado leste, nas laterais norte e sul. O sistema de refrigeração evaporativo era ligado e desligado automaticamente quando a temperatura do ar atingia, respectivamente, $26 \mathrm{e}$ $24^{\circ} \mathrm{C}$. O sistema era ajustado para manutenção da umidade entre 60 e $80 \%$

A edificação era composta por três linhas de celas parideiras, com piso plástico totalmente ripado, com uma área central para as fêmeas $(0,70 \mathrm{~m} \times 2,20 \mathrm{~m}), \mathrm{e}$, nas laterais, com duas áreas exclusivas para os leitões $(0,43 \mathrm{~m}$ x $2,20 \mathrm{~m})$. Cada gaiola possuía um escamoteador $(1,00 \mathrm{~m}$ x $0,45 \mathrm{~m})$ com piso aquecido.

As matrizes suínas híbridas foram escolhidas aleatoriamente nas três linhas de gaiolas, nas seguintes localizações: próximo aos painéis evaporativos: 12 fêmeas com ordem de parto (OP) de um a sete; no meio do galpão: 11 com OP de três a oito; e próximo aos exaustores: 11 com OP de um a seis. Elas receberam ração de lactação à base de milho e farelo de soja, com $19,6 \%$ de proteína bruta e $3.469,73 \mathrm{kcal}$ de EM por $\mathrm{kg}$. No dia do parto, a ração não foi oferecida; do segundo ao sétimo dia de lactação, a quantidade foi crescente, quando se estabilizou, e, a partir deste momento, a matriz recebeu, em média, $0,649 \mathrm{~kg} /$ leitão. A dieta foi fracionada e fornecida automaticamente às sete, 10,12 e 15 horas. Diariamente, o consumo de ração foi calculado pela diferença entre a quantidade de alimento fornecido e a sobra, e calculou-se o consumo médio diário. As matrizes e os leitões receberam água à vontade, em bebedouro tipo nipple.

As variáveis fisiológicas medidas na matriz suína foram realizadas de manhã e à tarde, em seis dias não consecutivos, iniciando um dia antes do parto previsto até o dia do desmame, realizadas pelo mesmo observador, após uma hora do arraçoamento das matrizes, totalizando 12 medidas por animal, por variável. A frequência respiratória foi medida pela contagem dos movimentos do flanco, com as matrizes em repouso, sem estarem amamentando e em decúbito. A temperatura superficial foi obtida atrás da orelha, no meio da escápula, na região mediana do dorso e no meio do pernil, com termômetro infravermelho (Instrutemp, modelo DT 8530 ), com variação de $-20^{\circ} \mathrm{C}$ a $530^{\circ} \mathrm{C}$, e calculou-se a média. Após 40 a 60 minutos da ingestão de ração, mediu-se a temperatura retal com termômetro clínico digital (Tech Line, modelo TS-101), faixa de $32^{\circ} \mathrm{C}$ a $42,9^{\circ} \mathrm{C}$ a cinco centímetros de profundidade, por dois minutos. Um dia antes do parto e no dia do desmame, mediu-se espessura de toucinho na posição P2 (na altura da última costela), aproximadamente a $6,5 \mathrm{~cm}$ da coluna vertebral com ultrassom (Microem, modelo MTU-100), com 2MHz pulsado. Registrou-se também o intervalo desmame-estro.

Depois da uniformização, que ocorreu 24 horas após o nascimento, fez-se a pesagem da leitegada em balança digital (Saint; 0,010kg a 50kg), bem como no desmame (Açores; $2 \mathrm{~kg}$ a $300 \mathrm{~kg}$ ), para se obter o ganho médio diário de massa corporal. A temperatura do ar, a umidade relativa e a temperatura de ponto de orvalho foram medidas a cada 30 minutos, por data loggers (Instrutherm, modelo HT-500), fora e dentro do galpão, nos seis dias das coletas das variáveis fisiológicas, durante o dia. Para isso, instalaramse nove data loggers, a $0,60 \mathrm{~m}$ de altura, divididos igualmente, próximo aos pads, ao centro e perto dos exaustores, e um data logger, fora do galpão, no abrigo termométrico. A velocidade do vento foi medida com anemômetro (Instruterm AD-250), colocado próximo das matrizes (Fig. 1). Calculou-se o índice de temperatura e umidade (ITU) conforme Thom (1959). 


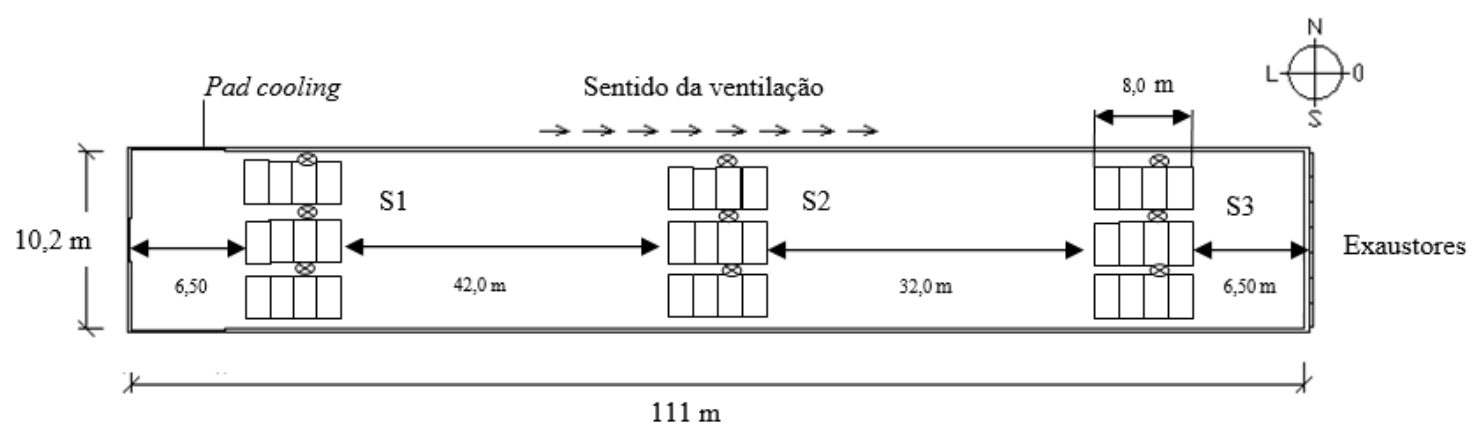

Figura 1. Representação esquemática mostrando os locais onde foram colocados os data loggers $(\otimes)$ nas diferentes localizações: próximo aos painéis evaporativos (setor leste, S1); no meio do galpão (meio, S2) e próximo aos exaustores (setor oeste, S3).

Os dados de desempenho produtivo foram avaliados pela ANCOVA, sendo ordem de parto e número de desmamados considerados covariáveis, após verificação do pressuposto de normalidade (teste de Lilliefors) e pressupostos de homogeneidade de variâncias (teste de Bartlett), e as médias foram comparadas pelo teste F. Para as variáveis que não alcançaram os pressupostos, mesmo após serem transformadas, utilizou-se o teste de Kruskal-Wallis, exceto dados fisiológicos de termorregulação de manhã e à tarde, em que se usou o teste de Wilcoxon. Realizou-se a correlação entre as variáveis fisiológicas de termorregulação com as variáveis temperatura e umidade do ar. Em todos os casos, $\alpha=0,05$.

Os valores médios da temperatura do ar e do ITU foram menores no setor leste em comparação ao meio do galpão e próximo aos exaustores (Tab. 1). O valor da Ta encontrados próximo aos pads cooling ficou dentro da zona termoneutra, entretanto, no centro e próximo aos exaustores, os valores da temperatura do ar estiveram no seu limite, conforme Auvigne et al. (2010), que citaram, para matrizes suínas, valor de até $25,0^{\circ} \mathrm{C}$. No entanto, em todas as localizações do galpão, a temperatura esteve acima da zona de termoneutralidade, conforme Williams et al. (2013), que consideraram valores ideais de 18 a $20^{\circ} \mathrm{C}$. O valor de ITU foi tido como normal (seguro), de acordo com Botto et al. (2014), porém, segundo Wegner et al. (2016) no meio do galpão e próximo aos exaustores seria classificado como crítico (>74-79) uma vez que estes autores classificaram sem estresse ITU $\leq 74$.

Tabela 1. Média, desvio-padrão, mínimo (Mín) e máximo (Máx) das variáveis do ambiente térmico em três localizações, em um galpão de maternidade para suínos, com resfriamento evaporativo combinado com pressão negativa, no verão, em ambiente tropical

\begin{tabular}{|c|c|c|c|c|c|c|c|c|c|c|c|}
\hline & \multirow[t]{2}{*}{$\mathrm{N}^{2}$} & \multicolumn{3}{|c|}{$\begin{array}{l}\text { Próximo aos pads } \\
\text { coolling- S1 }\end{array}$} & \multicolumn{3}{|l|}{ Meio - S2 } & \multicolumn{3}{|c|}{ Próximo aos exaustores- S3 } & \multirow{2}{*}{$\begin{array}{l}\mathrm{P} \\
\text { valor }\end{array}$} \\
\hline & & $\begin{array}{l}\text { Média } \\
\text { (desvio) }\end{array}$ & Mín & Máx & $\begin{array}{l}\text { Média } \\
\text { (desvio) }\end{array}$ & Mín & Máx & $\begin{array}{l}\text { Média } \\
\text { (desvio) }\end{array}$ & Mín & Máx & \\
\hline $\mathrm{Ta}\left({ }^{\circ} \mathrm{C}\right)^{1}$ & 450 & $22,38(1,16) \mathrm{a}$ & 20,6 & 24,2 & $24,56(1,62) b$ & 22,6 & 26,9 & $25,00(1,45) \mathrm{b}$ & 23,1 & 27,4 & $<0,01$ \\
\hline $\operatorname{UR}(\%)^{1}$ & 450 & $94,64(2,21) b$ & 88,7 & 96,8 & $86,70(2,90) \mathrm{a}$ & 79,7 & 90,3 & $87,29(3,66) \mathrm{a}$ & 79,6 & 92,0 & $<0,01$ \\
\hline $\mathrm{ITU}^{1}$ & 450 & $71,84(1,89) \mathrm{a}$ & 69,3 & 74,0 & $74,82(2,47) \mathrm{b}$ & 71,5 & 77,1 & $75,62(2,12) b$ & 72,3 & 77,7 & $<0,01$ \\
\hline
\end{tabular}

${ }^{1}$ Médias seguidas pela mesma letra, na linha, diferem entre si pelo teste de Kruskal-Wallis. Ta temperatura do ar; UR - umidade relativa; ITU - índice de temperatura e umidade. ${ }^{2} \mathrm{~N}$ - número de observações.

Independentemente da localização dentro do galpão de maternidade, o comportamento da temperatura do ar e do ITU aumentou do período da manhã para o da tarde (Fig. 2A e 2C). A temperatura externa teve comportamento semelhante, porém com maior amplitude térmica (Fig. 2D). 
O comportamento da umidade relativa foi inverso ao da temperatura e do ITU (Fig. 2B). Esse resultado era esperado, uma vez que a sua variação ocorre por causa das alterações na temperatura. A umidade nas três localizações esteve acima da condição ideal para suínos, que não deve ultrapassar 70\% (Sampaio et al., 2004).
Também Morales et al. (2013) verificaram maior valor médio de umidade em galpões com painéis evaporativos em comparação àqueles com resfriamento sobre a cabeça e com manejo de cortina $(88,3 ; 74,5 ; 73,6 \%$, respectivamente). A velocidade do vento na altura das matrizes foi nula.
A) Temperatura $\left({ }^{\circ} \mathrm{C}\right)$ (dentro do galpão)

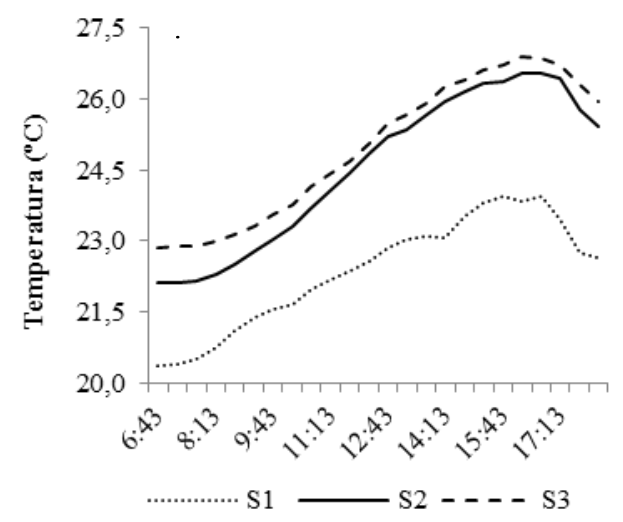

C) ITU (dentro do galpão)

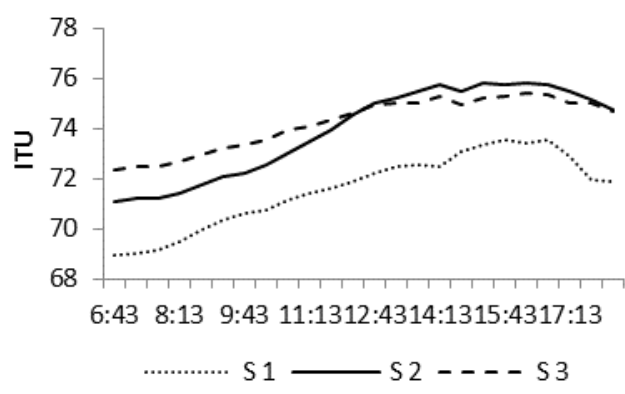

B) Umidade relativa (\%) (dentro do galpão)

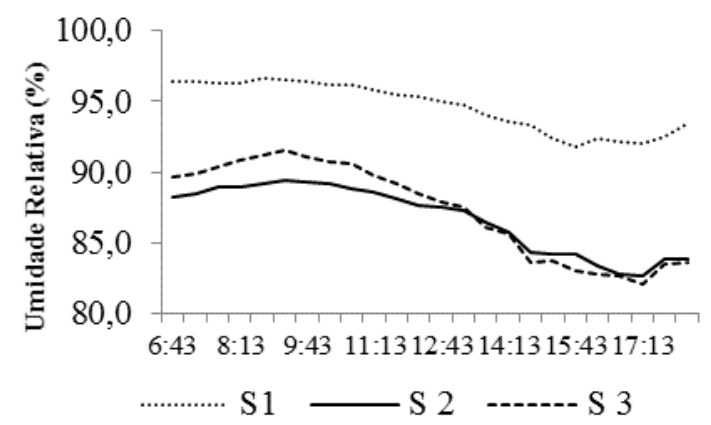

D) Data logger (fora do galpão)

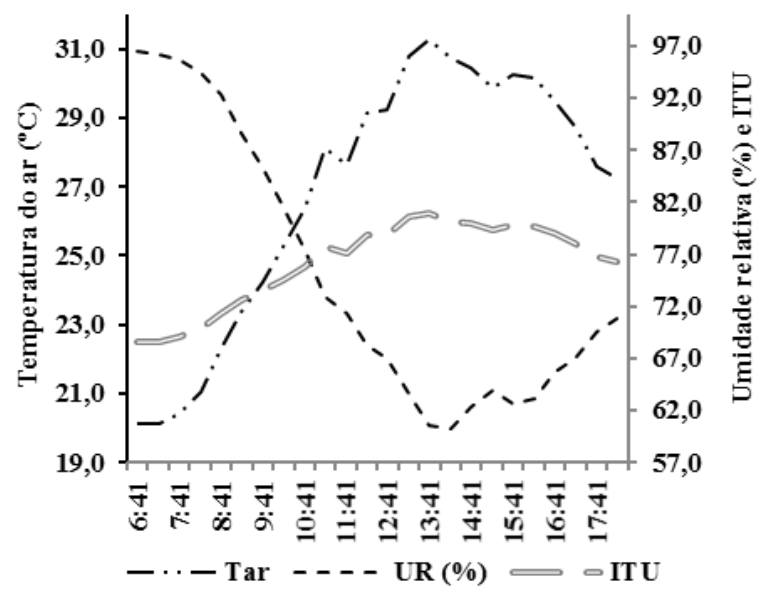

Figura 2. Ambiente térmico a cada 30 minutos, dentro e fora do galpão de maternidade, para matrizes suínas no período diurno ( $\mathrm{S} 1=$ próximo aos pads cooling; $\mathrm{S} 2=$ meio do galpão e $\mathrm{S} 3=$ próximo aos exaustores).

Matrizes alojadas próximo aos pads cooling apresentaram frequência respiratória e temperatura superficial menores que aquelas localizadas no centro e próximo aos exaustores (Tab. 2). Esses resultados eram esperados, uma vez que a Ta e o ITU próximo aos pads foram menores que nos demais locais do galpão. A temperatura superficial é influenciada pela temperatura do ar e pela vasodilatação periférica que ocorre em resposta à temperatura ambiente elevada, e, quando a diferença entre a temperatura superficial e a do ambiente for maior, então, maior será a dissipação de calor pelos mecanismos sensíveis de calor. Já a frequência respiratória é uma boa medida para verificar se os animais estão ou não sob estresse 
por calor, e, no setor leste (pads), o ambiente térmico esteve dentro da zona termoneutra. Justino et al. (2014), ao estudarem o resfriamento da nuca de porcas em lactação, observaram redução da frequência respiratória e da temperatura superficial de animais sob resfriamento da região da cabeça em comparação àqueles que receberam somente ventilação natural na cabeça $\left(46,68\right.$ vs. 62,55 mov. $\min ^{-1} \mathrm{e}$ 34,33 vs. $34,79^{\circ} \mathrm{C}$, respectivamente). Portanto, o sistema de resfriamento pode influenciar na frequência respiratória e na temperatura superficial.

O valor de frequência respiratória das matrizes próximas aos pads foi inferior ao encontrado por Corassa et al. (2014) em matrizes no último estágio de lactação $\left(48,06 \mathrm{mov}^{\mathrm{min}} \mathrm{m}^{-1}\right)$, criadas em galpão com ventilação natural manejado por abertura e fechamento de cortinas ( $\mathrm{Ta}$ de $26,97^{\circ} \mathrm{C}$ e UR de $78,86 \%$ ), e superior ao encontrado em animais alojados no meio e próximo aos exaustores. As médias de FR foram inferiores às encontradas por Martins et al. (2008), que foram de 74,8mov. $\mathrm{min}^{-1}$ a uma Ta média de $27,8^{\circ} \mathrm{C}$ e umidade de $75,3 \%$ em galpão de maternidade, com cortinas laterais (abertas às $7 \mathrm{~h} 30$ e fechadas às 18h), e equipado com ventiladores (acionados, rotineiramente, das 11 às $16 \mathrm{~h}$ ). Os valores da frequência respiratória observada por Justino et al. (2014) em porcas em lactação, com resfriamento da região da cabeça $\left(46,68 \mathrm{mov}^{\mathrm{min}}{ }^{-1}\right)$, foram próximos aos obtidos no presente estudo, em matrizes alojadas próximo aos pads coolling, e abaixo dos obtidos nos animais do meio e próximo aos exaustores. O valor da FR neste estudo foi superior aos encontrados por Williams (2009) em porcas sob conforto térmico $\left(18\right.$ a $\left.20^{\circ} \mathrm{C}\right)\left(33,74 \mathrm{mov}^{\mathrm{min}}{ }^{-1}\right)$, primíparas, Landrace e Landrace x Large White, em câmara climática, porém inferior àquelas sob estresse por calor $\left(24\right.$ a $\left.30^{\circ} \mathrm{C}\right)\left(62,90 \mathrm{mov}^{\circ} \mathrm{min}^{-1}\right)$. Então, as divergêngias observadas para FR podem ser explicadas, em parte, pelo uso de diferentes sistemas de resfriamento.

Tabela 2. Média, desvio-padrão, mínimo (Mín) e máximo (Máx) das variáveis fisiológicas de fêmeas suínas lactantes em diferentes localizações, em um galpão de maternidade com resfriamento evaporativo combinado com pressão negativa, no verão, em ambiente tropical

\begin{tabular}{|c|c|c|c|c|c|c|c|c|c|c|}
\hline & \multicolumn{3}{|c|}{$\begin{array}{l}\text { Próximo aos pads } \\
\text { coolling }\end{array}$} & \multicolumn{3}{|c|}{ Meio do galpão } & \multicolumn{3}{|c|}{ Próximo aos exaustores } & \multirow{2}{*}{$\begin{array}{l}\mathrm{P} \\
\text { valor }\end{array}$} \\
\hline & $\begin{array}{l}\text { Média } \\
\text { (desvio) }\end{array}$ & Mín & Máx & $\begin{array}{l}\text { Média } \\
\text { (desvio) }\end{array}$ & Mín & Máx & $\begin{array}{l}\text { Média } \\
\text { (desvio) }\end{array}$ & Mín & Máx & \\
\hline $\begin{array}{l}\text { FR (mov.m- } \\
\left.1{ }^{-}\right)\end{array}$ & $\begin{array}{l}43,67 \\
(18,28) \mathrm{a}\end{array}$ & 12 & 108 & $\begin{array}{l}52,04 \\
(19,30) b\end{array}$ & 16 & 96 & $\begin{array}{l}56,38 \\
(19,66) \mathrm{b}\end{array}$ & 16 & 112 & $<0,01$ \\
\hline $\mathrm{TS}\left({ }^{\circ} \mathrm{C}\right)$ & $29,51(2,55) \mathrm{a}$ & 21,2 & 35,5 & $32,02(1,56) \mathrm{b}$ & 27,9 & 35,5 & $32,56(1,65) \mathrm{b}$ & 27,8 & 36,2 & $<0,01$ \\
\hline TR $\left({ }^{\circ} \mathrm{C}\right)$ & $38,40(0,37) \mathrm{a}$ & 38,0 & 40,3 & $38,48(0,55) \mathrm{a}$ & 37,5 & 40,9 & $38,93(0,58) b$ & 38,0 & 40,8 & $<0,01$ \\
\hline
\end{tabular}

Médias seguidas pela mesma letra, na linha, diferem entre si pelo teste de Kruskal-Wallis. FR - frequência respiratória; mov. $\mathrm{m}^{-1}$ - movimentos respiratórios por minuto; TS - temperatura superficial; TR - temperatura retal.

A temperatura retal das matrizes alojadas próximo aos pads cooling e ao centro foi inferior às localizadas próximo aos exaustores (Tab. 2). Apesar de todos os valores dessa variável estarem dentro da normalidade para a espécie, seu maior valor em matrizes alojadas próximo aos exaustores pode ter sido uma ineficiência na sua termorregulação. Os valores observados neste estudo foram superiores ao verificado por Malmkvist et al. (2012) em matrizes suínas lactantes, de primeira a terceira ordem de parto, criadas sob temperatura ambiente de $20^{\circ} \mathrm{C}$ $\left(38,0^{\circ} \mathrm{C}\right)$, entretanto foram inferiores ao de matrizes criadas a $25^{\circ} \mathrm{C}\left(39,0^{\circ} \mathrm{C}\right)$. Williams et al. (2009) encontraram valores de 39,22 e $39,44^{\circ} \mathrm{C}$, respectivamente, para porcas sob conforto $(18 \mathrm{a}$ $20^{\circ} \mathrm{C}$ ) e sob estresse por calor $\left(24\right.$ a $\left.30^{\circ} \mathrm{C}\right)$, primíparas, Landrace e Landrace x Large White, valores esses superiores aos obtidos no presente estudo. Robinson (2004) cita valor de $39,1^{\circ} \mathrm{C}$, e Martins et al. (2008) de $39,2^{\circ} \mathrm{C}$ a uma Ta média de $27,8^{\circ} \mathrm{C}$ e UR de $75,3 \%$, valores superiores aos obtidos neste estudo.

Justino et al. (2014), ao avaliarem as respostas fisiológicas em fêmeas suínas lactantes em sistema de resfriamento da cabeça, encontraram temperatura retal de $38,8^{\circ} \mathrm{C}$, temperatura de superfície de $34,3^{\circ} \mathrm{C}$ e frequência respiratória de 46,7 mov. min $^{-1}$ (temperatura do ar de $24,2^{\circ} \mathrm{C}$ e umidade de 79,5\%), valores próximos aos encontrados no presente estudo, em que foi 
usado o SRE com pad cooling. Malmkvist et al. (2012) também observaram aumento das temperaturas retal e superficial e da frequência respiratória quando a temperatura ambiente da maternidade aumentou de 15,0 para $25,0^{\circ} \mathrm{C}$. Também Kiefer et al. (2010), que estudaram suínos castrados mantidos em ambiente quente $\left(32^{\circ} \mathrm{C}\right)$, verificaram maior temperatura retal em relação àqueles mantidos em ambiente de $21^{\circ} \mathrm{C}$ e concluíram que essas variáveis fisiológicas aumentaram proporcionalmente com a elevação da temperatura ambiente.

A localização da matriz suína dentro do galpão com sistema de resfriamento evaporativo pad cooling não influenciou na espessura de toucinho, no intervalo desmame-estro, no consumo de ração, na massa corporal inicial e final dos leitões, no número de desmamados e no ganho de massa corporal diário dos leitões (Tab. 3). Esses resultados podem ser explicados, primeiro, possivelmente porque o consumo diário de ração bem como os seus nutrientes foram suficientes para o bom desempenho, segundo, porque os efeitos do estresse por calor dependem da duração e de sua intensidade, portanto o ambiente térmico no centro e próximo aos exaustores, apesar de ter influenciado negativamente as variáveis de termorregulação, não foi suficiente para prejudicar o desempenho.
Entretanto, ao se considerar o bem-estar animal (BEA), em que uma das cinco liberdades é o conforto, as fêmeas suínas no centro e próximo aos exaustores possivelmente tiveram BEA prejudicado. É importante mencionar também que as condições meteorológicas dentro do galpão com o SRE pad cooling foram mais adequadas que as encontradas no meio externo (Fig. 2D), portanto esse sistema amenizou a influência dos fatores climáticos. Justino et al. (2015) também verificaram que matrizes criadas em sistema de ventilação natural e em sistema de resfriamento da cabeça, criadas no mesmo galpão, apresentaram desempenhos produtivo e reprodutivo semelhantes. Entretanto, Farmer et al. (2007) verificaram maior consumo de ração sob $21^{\circ} \mathrm{C}$ em comparação às porcas lactantes mantidas sob $29^{\circ} \mathrm{C}\left(4,6\right.$ vs. 3,8kg.dia $\left.{ }^{-1}\right)$. Uma explicação para essa divergência de resultados pode ser a intensidade do estresse, que foi acima da temperatura média observada no presente estudo, e também a duração do estresse. Outra possível explicação é quanto à quantidade e aos nutrientes da ração, que provavelmente foram suficientes para o bom desempenho no presente estudo. O consumo médio diário de ração esteve acima do encontrado por Campos et al. (2008) para matriz lactante híbrida, que foi de $6,520 \mathrm{~kg}$, em Ta média de $23,5^{\circ} \mathrm{C}$.

Tabela 3. Média, desvio-padrão, mínimo (Mín) e máximo (Máx) das variáveis de desempenho de fêmeas suínas lactantes em três locais (setor), em um galpão com resfriamento evaporativo combinado com pressão negativa, no verão, em ambiente tropical

\begin{tabular}{|c|c|c|c|c|c|c|c|c|c|c|}
\hline & \multicolumn{3}{|c|}{$\begin{array}{l}\text { Próximo ao pad cooling } \\
\text { (S1) }\end{array}$} & \multicolumn{3}{|c|}{ Meio do galpão -S2 } & \multicolumn{3}{|c|}{$\begin{array}{l}\text { Próximo aos exaustores - } \\
\text { S3 }\end{array}$} & \multirow{2}{*}{$\begin{array}{l}\mathrm{P}- \\
\text { valor }\end{array}$} \\
\hline & $\begin{array}{l}\text { Média } \\
\text { (desvio) }\end{array}$ & Mín & Máx & $\begin{array}{l}\text { Média } \\
\text { (desvio) }\end{array}$ & Mín & Máx & $\begin{array}{l}\text { Média } \\
\text { (desvio) }\end{array}$ & Mín & Máx & \\
\hline $\mathrm{ET} \mathrm{parto}^{2}(\mathrm{~mm})$ & $\begin{array}{l}16,92 \\
(4,14)\end{array}$ & 11,00 & 26,00 & $19,73(4,65)$ & 15,00 & 28,0 & $\begin{array}{l}19,18 \\
(4,02)\end{array}$ & 12,0 & 24,0 & $\mathrm{~ns}^{3}$ \\
\hline ET desm. ${ }^{2}(\mathrm{~mm})$ & $\begin{array}{l}16,42 \\
(2,87)\end{array}$ & 11,00 & 20,00 & $19,00(5,44)$ & 12,00 & 26,0 & $\begin{array}{l}17,45 \\
(3,24)\end{array}$ & 11,0 & 21,0 & ns \\
\hline Dif. $^{2}(m m)$ & $-0,50(2,47)$ & $-6,0$ & 2,0 & $-0,73(3,04)$ & $-5,0$ & 5,0 & $-1,73(1,74)$ & $-4,0$ & 2,0 & ns \\
\hline IDE (dias) & $4,1(0,5)$ & 4,0 & 5,0 & $5,0(2,3)$ & 4,0 & 10,0 & $5,0(1,5)$ & 4,0 & 9,0 & $\mathrm{~ns}$ \\
\hline $\mathrm{CMD}^{2}(\mathrm{~kg})$ & $\begin{array}{l}7,366 \\
(0,291)\end{array}$ & 6,833 & 7,690 & $\begin{array}{l}6,902 \\
(0,477)\end{array}$ & 6,156 & 7,500 & $\begin{array}{l}7,388 \\
(0,525)\end{array}$ & 6,386 & 8,159 & ns \\
\hline MCI leit. ${ }^{2}(\mathrm{~kg})$ & $\begin{array}{l}1,413 \\
(0,246)\end{array}$ & 0,918 & 1,720 & $\begin{array}{l}1,501 \\
(0,285)\end{array}$ & 0,985 & 1,874 & $\begin{array}{l}1,431 \\
(0,317)\end{array}$ & 0,778 & 1,744 & ns \\
\hline MCF leit. ${ }^{2}(\mathrm{~kg})$ & $\begin{array}{l}5,100 \\
(0,890)\end{array}$ & 3,989 & 6,730 & $\begin{array}{l}5,590 \\
(0,930)\end{array}$ & 3,293 & 6,884 & $\begin{array}{l}5,470 \\
(1,050)\end{array}$ & 3,574 & 6,753 & ns \\
\hline $\mathrm{N}^{\circ}$ desm. ${ }^{4}$ & $12,0(0,85)$ & 11,0 & 13,0 & $10,9(2,3)$ & 8,0 & 16,0 & $12,7(1,6)$ & 10,0 & 15,0 & \\
\hline $\begin{array}{l}\text { GMC leit. }{ }^{2} \\
\text { (kg/dia) }\end{array}$ & $\begin{array}{l}0,184 \\
(0,403)\end{array}$ & 0,134 & 0,265 & $\begin{array}{l}0,209 \\
(0,412)\end{array}$ & 0,121 & 0,279 & $\begin{array}{l}0,189 \\
(0,325)\end{array}$ & 0,133 & 0,232 & ns \\
\hline
\end{tabular}

${ }^{2}$ Médias comparadas pelo teste F. ET - espessura de toucinho; desm- desmama; Dif. - diferença entre ET parto e ET desm.; IDE - intervalo desmame-estro; CMD - consumo médio diário; MCI leit. - massa corporal inicial da leitegada; MCF leit. - massa corporal final da leitegada; $\mathrm{N}^{\circ}$ desm. - número de desmamamdos; GMC leit. - ganho de massa corporal médio diário da leitegada. ${ }^{3} \mathrm{~ns}=$ não significativo. ${ }^{4}$ Covariável. 
Leitões nas diferentes localizações apresentaram massa corporal ao desmame e ganho médio diário semelhantes (Tab. 3). Esse resultado pode ser explicado, em parte, pelo fato de o consumo de alimentos das matrizes não ter diferido entre si e também por se manter normal e em quantidade adequada para lactação. Morales et al. (2013) expuseram um grupo de matrizes lactantes em galpão com sistema de resfriamento evaporativo com pressão negativa (SRE) a $23,1^{\circ} \mathrm{C}$, um grupo com resfriamento na nuca $(\mathrm{RN})$ a $26,8^{\circ} \mathrm{C}$ e em galpão com manejo de cortinas $(\mathrm{MC})$ a $26,8^{\circ} \mathrm{C}$. Os autores verificaram que o consumo de ração foi maior nos animais em SRE (5,1 kg.dia $\left.{ }^{-1}\right)$ e RN $\left(5,2 \mathrm{~kg} \cdot \mathrm{dia}^{-1}\right)$ em relação à MC $\left(4,7 \mathrm{~kg} \cdot \operatorname{dia}^{-1}\right)$, apesar de a temperatura do ar ser igual entre $\mathrm{RN}$ e $\mathrm{MC}$, e explicaram que o maior consumo em RN foi por causa do ar fresco sobre a cabeça, que auxiliou na termorregulação e no conforto das porcas. Observaram ainda que a massa corporal dos leitões ao desmame não diferiu entre grupos e foi de $6,152 \mathrm{~kg}$ para SRE, 6,209kg para RN e $5,977 \mathrm{~kg}$ para MC. No entanto, Perin et al. (2016) observaram maior consumo de ração em porcas lactantes sob sistema de resfriamento na nuca $\left(25,8^{\circ} \mathrm{C}\right)$ em relação às criadas sob sistema convencional $\left(26,1^{\circ} \mathrm{C}\right) \quad(4,8$ vs. $5,8 \mathrm{~kg}) \quad \mathrm{e}$ explicaram que o melhor desempenho dos leitões das matrizes alojadas sob o sistema de resfriamento na nuca se deveu ao melhor conforto térmico promovido pelo ar frio sobre os animais, conclusão semelhante à de Morales et al. (2013). A utilização do sistema de resfriamento evaporativo tem ação direta na redução dos efeitos das altas temperaturas sobre as variáveis ligadas à termorregulação em porcas em lactação durante os períodos quentes do ano e proporciona melhores pesos dos leitões ao desmame (Justino et al., 2015; Perin et al., 2016).

As médias de todas as variáveis fisiológicas, da Ta e do ITU foram menores no período da manhã em comparação ao período da tarde (Tab. 4). Possivelmente, o aumento das variáveis de termorregulação ocorreu em razão do acréscimo da Ta, que possui uma ação direta sobre a produção e a dissipação de calor. Adicionalmente, observou-se correlação positiva e significativa entre as variáveis fisiológicas e a Ta (Tab. 5), o que indica que o aumento de Ta leva ao acréscimo das variáveis fisiológicas de termorregulação.

Tabela 4. Média e desvio-padrão de variáveis ambientais e fisiológicas de fêmeas suínas lactantes em três localizações, em um galpão com resfriamento evaporativo combinado com pressão negativa, de manhã e à tarde

\begin{tabular}{lllllll}
\hline & $\begin{array}{l}\text { FR } \\
\left(\mathrm{mov} \min ^{-1}\right)\end{array}$ & TS $\left({ }^{\circ} \mathrm{C}\right)$ & TR $\left({ }^{\circ} \mathrm{C}\right)$ & UR $(\%)$ & Ta $\left({ }^{\circ} \mathrm{C}\right)$ & ITU \\
\hline Manhã & $48,71 \mathrm{a}(20,71)$ & $30,26 \mathrm{a}(3,88)$ & $38,43 \mathrm{a}(3,82)$ & $91,85 \mathrm{~b}(3,41)$ & $22,70 \mathrm{a}(1,09)$ & $72,16 \mathrm{a}(1,33)$ \\
Tarde & $52,11 \mathrm{~b}(20,19)$ & $32,33 \mathrm{~b}(4,83)$ & $38,76 \mathrm{~b}(5,42)$ & $87,56 \mathrm{a}(4,84)$ & $25,17 \mathrm{~b}(1,53)$ & $75,90 \mathrm{~b}(1,79)$ \\
P valor & 0,0443 & $<0,01$ & $<0,01$ & $<0,01$ & $<0,01$ & $<0,01$ \\
\hline
\end{tabular}

Médias seguidas por letras minúsculas na mesma coluna diferem pelo teste de Wilcoxon, a 5\%. FR - frequência respiratória; mov.min-1 - movimentos respiratórios por minuto; TS - temperatura superficial; TR - temperatura retal; UR - umidade relativa; Ta - temperatura do ar; ITU - índice de temperatura e umidade.

Tabela 5. Coeficiente de correlação entre as variáveis fisiológicas de matrizes suínas e variáveis do ambiente térmico

\begin{tabular}{llll} 
& $\begin{array}{l}\text { Ta } \\
\text { (temperatura do ar) }\end{array}$ & $\begin{array}{l}\text { UR } \\
\text { (umidade relativa) }\end{array}$ & $\begin{array}{l}\text { ITU } \\
\text { (índice de temperatura e umidade) }\end{array}$ \\
\hline FR (frequência respiratória) & $0,305^{*}$ & $-0,242^{*}$ & $0,308^{*}$ \\
TS (temperatura superificial) & $0,679^{*}$ & $-0,569^{*}$ & $0,685^{*}$ \\
TR (temperatura retal) & $0,437^{*}$ & $-0,345^{*}$ & $0,438^{*}$ \\
\hline
\end{tabular}

$* \mathrm{P}<0,001$, em que: $<0,5$, baixa; 0,5 a 0,8 , média; > 0,8, alta. $\mathrm{FR}=$ frequência respiratória; $\mathrm{TS}=$ temperatura superficial e $\mathrm{TR}=$ temperatura retal.

Justino et al. (2014) encontraram frequência respiratória e temperatura superficial menores em fêmeas suínas lactantes sob sistema de resfriamento da cabeça $\left(46,68\right.$ mov. $\mathrm{min}^{-1}$ e $34,33^{\circ} \mathrm{C}$, respectivamente) em relação ao sistema de ventilação natural $\left(62,55 \mathrm{mov} \cdot \mathrm{min}^{-1} \mathrm{e}\right.$ $34,79^{\circ} \mathrm{C}$ ), e a temperatura retal não diferiu entre os sistemas de resfriamento $\left(38,81\right.$ vs. $\left.38,97^{\circ} \mathrm{C}\right)$. 
A temperatura ambiente no galpão de resfriamento da nuca $\left(24,15^{\circ} \mathrm{C}\right)$ foi menor que com ventilação natural $\left(26,25^{\circ} \mathrm{C}\right)$. A hora do dia influencia as variáveis fisiológicas, assim Corassa et al. (2014), em galpão de maternidade com ventilação natural, sob temperaturas de 24,94 a $30,81^{\circ} \mathrm{C}$, obtiveram frequência respiratória para porcas em lactação de 64,35; 49,00; 38,60 e 28,35mov. $\mathrm{min}^{-1}$, respectivamente, à tarde, de manhã, à noite e na madrugada. A temperatura retal foi maior nos horários de $15 \mathrm{~h}$ $\left(39,24^{\circ} \mathrm{C}\right)$ e $21 \mathrm{~h}\left(39,32^{\circ} \mathrm{C}\right)$ em relação aos horários de nove horas $\left(38,67^{\circ} \mathrm{C}\right)$ e três horas $\left(38,87^{\circ} \mathrm{C}\right)$. Os mesmos autores esclareceram que, nos horários mais quentes do dia, essas variáveis se mantêm elevadas, na tentativa de o animal ajustar sua homeotermia. Gourdine et al. (2006), em Guadalupe, latitude $16^{\circ} \mathrm{N}$ e longitude $61^{\circ} \mathrm{W}$, encontraram maior temperatura retal em fêmeas suínas lactantes na estação muito quente (novembro a abril) em relação à estação quente (maio a outubro) $\left(38,9^{\text {vs. }} 38,6^{\circ} \mathrm{C}\right)$, com temperaturas ambientes médias de 26,0 e $24,1^{\circ} \mathrm{C}$, respectivamente.

Os valores de umidade foram superiores de manhã em relação à tarde (Tab. 4). Também Morales et al. (2013) observaram flutuações que alcançaram $90,5 \%$ e $85,5 \%$ para os períodos matutino e vespertino, respectivamente, em galpão com SRE com pressão negativa. As correlações entre as variáveis fisiológicas com a
Ta e o ITU (Tab. 5) foram significativas, positivas e de baixa a média magnitude. Também Brown-Brandl et al. (2012) verificaram que, quando há um aumento da temperatura do ar acima de $22^{\circ} \mathrm{C}$ (no presente estudo, no centro e próximo aos exaustores), ocorre um aumento na frequência respiratória, a qual contribui para o aumento da perda de calor por evaporação, o que auxilia no controle da temperatura corporal profunda. As correlações entre umidade $\mathrm{e}$ parâmetros fisiológicos foram significativas, negativas e de baixa a média magnitude, indicando que um aumento da umidade pode levar a maiores valores das variáveis fisiológicas.

Em ambiente tropical, no verão, as condições meteorológicas num galpão de maternidade para matrizes suínas, com sistema de resfriamento evaporativo pad cooling com pressão negativa, não são homogêneas. No verão, no período diurno, a localização próxima aos pads coolings caracteriza um ambiente termoneutro, no entanto o centro e o próximo aos exaustores caracterizam desconforto térmico. $\mathrm{O}$ ambiente térmico no meio e próximo aos exaustores influencia negativamente os parâmetros fisiológicos de termorregulação, porém não prejudica o desempenho das matrizes e da leitegada.

Palavras-chave: suíno, Sus scrofa, zona termoneutra, temperatura retal, leitão

\begin{abstract}
The effects of housing lactating sows at different locations in a shed with evaporative cooling system (ECS) on their thermoregulation and reproductive and productive performance of the sow and the litter in summer were determined. 34 females were used in the three lines of cages at these locations: near the pad cooling; in the middle of the shed and near the exhaust fans. The air temperature and the temperature and humidity index (THI) were lower near the pad cooling $\left(22.38^{\circ} \mathrm{C}, 71.84\right)$ than the middle $\left(24.56^{\circ} \mathrm{C}, 74.82\right)$ and near the exhaust fans $\left(25.00^{\circ} \mathrm{C}, 75.62\right)$. Respiratory rate, rectal and surface temperatures were lower in sows near the pad cooling $\left(43.67\right.$ breaths. $\left.\mathrm{min}^{-1}, 38.40^{\circ} \mathrm{C} ; 29.51^{\circ} \mathrm{C}\right)$ than in the center $\left(52.04\right.$ breaths. min $\left.^{-1} ; 38.48^{\circ} \mathrm{C} ; 32.02^{\circ} \mathrm{C}\right)$ and near the exhaust fans $(56.38$ breaths.min-1, $38.93^{\circ} \mathrm{C} ; 32.52^{\circ} \mathrm{C}$ ). The backfat thickness, the weaning-estrus interval and daily average consumption of the sows, number of weaning piglets, corporal mass and daily average gain of the piglets were not influenced by the location of housing in the shed. Lactating sows housed in the middle and near the exhaust fans in the ECS presented increased thermoregulation physiological variables, however, this did not impair the performance.
\end{abstract}

Keywords: swine, Sus scrofa, thermoneutral zone, rectal temperature, piglet 


\section{REFERÊNCIAS}

AUVIGNE, V.; LENEVEU, P.; JEHANNIN, C. et al. Seasonal infertility in sows: a five year field study to analyze the relative roles of heat stress and photoperiod. Theriogenology, v.74, p.60-66, 2010.

BOTTO, L.; LENDELOVA, J.; STRMENOVA, A. et al. The effect of evaporative cooling on climatic parameters in a stable for sows. Res. Agric. Eng., v.60, p.S85-S91, 2014

BROWN-BRANDL, T.M.; EIGENBERG, R.A.; PURSWELL, J.L. Determining heat tolerance in finishing pigs using thermal imaging. In: INTERNATIONAL LIVESTOCK ENVIRONMENT SYMPOSIUM, 9., 2012, Valencia. Proceedings... Valencia: ASABE, 2012. p.8.

CAMPOS, J.A.; TINÔCO, I.F.F; BAÊTA, F.C. et al. Ambiente térmico e desempenho de suínos em dois modelos de maternidade e creche. Rev. Ceres, v.55, p.187-193, 2008.

CORASSA, A.; DAL MAGRO, T.R.D.; KOMIYAMA, C.M. et al. Comportamento e parâmetros fisiológicos de porcas em lactação na transição Cerrado-Amazônia. Comum. Sci., v.5, p.286294, 2014.

FARMER, C.; KNIGHT, C.; FLINT, D. Mammary gland involution and endocrine status in sows: Effects of weaning age and lactation heat stress. Can. J. Anim. Sci., v.87, p.35-43, 2007.

GOURDINE, J.L.; BIDANEL, J.P.; NOBLET, J. et. $a l$. Effect of breed and season performance of lactating sows in a tropical humid climate. J. Anim. Sci., 84, p.360-369, 2006.

JUSTINO, E.; NÄÄS, I.A.; CARVALHO, T.M.R. et al. Efeito do resfriamento evaporativo e do balanço eletrolítico sobre a lactação de porcas em condições de verão tropical. Arq. Bras. Med. Vet. Zootec., v.67, p.455-464, 2015.

JUSTINO, E.; NÄÄS, I.A.; CARVALHO, T.M.R. et al. The impact of evaporative cooling on the thermoregulation and sensible heat loss of sows during farrowing. Eng. Agríc., v.34, P.1050-1061, 2014.

KIEFER, C.; MOURA, M.S.; SILVA, E.A. et al. Respostas de suínos em terminação mantidos em diferentes ambientes térmicos. Rev. Bras. Saúde Prod. An., v.11, p.496-504, 2010.
MALMKVIST, J.; PEDERSEN, L.J.; KAMMERSGAARD, T.S. et al. Influence of thermal environment on sows around farrowing and during the lactation period. J. Anim. Sci., v.90, p.3186-3199, 2012

MARTINS, T.D.D.; COSTA, A.N.; SILVA, J.H.V. Respostas termorreguladoras de matrizes suínas híbridas em lactação, mantidas em ambiente quente. Ciênc. agrotec., v.32, p.961-968, 2008.

MORALES, O.E.S.; GONÇALVES, M.A.D.; STORTI, A.A. et al. Effect of different systems for the control of environmental temperature on the performance of sows and their litters. Acta Sci. Vet., v.41, p.1-8, 2013.

PERIN, J.; GAGGINI, T.S.; MANICA, S. et al. Evaporative snout cooling system on the performance of lactating sows and their litters in a subtropical region. Ciênc. Rural, v.46, p.342-347, 2016.

ROBINSON, N.E. Homeostase - termorregulação. In: CUNNINGHAM, J.G. Tratado de fisiologia veterinária. 3.ed. Rio de Janeiro: Guanabara Koogan, 2004. p.550-560.

SAMPAIO, C.A.P.; CRISTIANI, J.; DUBIELA, J.A. et al. Avaliação do ambiente térmico em instalações para crescimento e terminação de suínos utilizando os índices de conforto térmico nas condições tropicais. Ciênc. Rural, v.34, p.784-790, 2004.

THOM, E.C. The discomfort index. Weatherwise, v.12, p.57-60, 1959

WEGNER, K.; LAMBERTZ, C.; DAS, G. et al. Effects of temperature and temperature-humidity index on the reproductive performance of sows during summer months under a temperate climate. Anim. Sci. J., v.87, 1334-1339, 2016.

WILLIAMS, A.M.; SAFRANSKI, T.J.; SPIERS, D.E. et al. Effects of a controlled heat stress during late gestation, lactation, and after weaning on thermoregulation, metabolism, and reproduction of primiparous sows. J. Anim. Sci., v.91, p.2700-2714, 2013

WILLIAMS, A.M. Effects of heat stress on reproduction and productivity of primiparous sows and their piglets' performance. 2009. 136f. Tese (Master of Science). Faculty of the Graduate School, University of Missouri-Columbia. 